\title{
Brand Image and Brand Dilution in the Fashion Industry
}

\author{
Peter M. Kort \\ Tilburg University, Department of Econometrics and Operations Research \& CentER, \\ Tilburg, The Netherlands, and \\ University of Antwerp, Department of Economics, Antwerp, Belgium \\ Jonathan P. Caulkins \\ Carnegie Mellon University, \\ H. John Heinz III School of Public Policy \& Management, Pittsburgh, PA, USA \\ Richard F. Hartl \\ University of Vienna, Department of Business Studies, Vienna, Austria \\ Gustav Feichtinger
}

Vienna University of Technology, Department of Operations Research and Systems Theory,

Vienna, Austria

July 20, 2005

\begin{abstract}
We develop a dynamic optimal control model of a fashion designer's challenge of maintaining brand image in the face of short-term profit opportunities through expanded sales that risk brand dilution in the longer-run. The key state variable is the brand's reputation, and the key decision is sales volume. Depending on the brand's capacity to command higher prices, one of two regimes is observed. If the price mark-ups relative to production costs are modest, then the optimal solution may simply be to exploit whatever value can be derived from the brand in the short-run and retire the brand when that capacity is fully diluted. However, if the price markups are more substantial, then an existing brand should be preserved.
\end{abstract}


It may even be worth incurring short-term losses while increasing the brand's reputation, even if starting a new brand name from scratch is not optimal.

\section{Introduction}

People pay more for brand-name products than they do for essentially identical products lacking brand identity. Sometimes this pertains to brand as a signal of quality (e.g., Maytag washing machines). However, brand-name markups are particularly pronounced in the fashion industry where functionality is less important than the brand's signal of style and exclusivity. If Gucci products are very expensive, then people who display their consumption of Gucci products are signaling their wealth to all observers (Bikhchandani et al., 1992; Coelho and McClure, 1993; Bagwell \& Bernheim, 1996; Frijters, 1998; Corneo and Jeanne, 1999; Bianchi, 2002). From marketing textbooks we know that the price of prestige goods should not be too low, because demand could be lower at a lower price (e.g., Berkowitz et al., 2000; Boone and Kurtz, 1999; Perreault and McCarthy, 2000).

Physically attaching a brand-name to a product costs little, so the brand's capacity to command higher prices translates into substantial profit opportunities. This capacity is name-specific; merely sewing the name "Joe Smith" on a sweater won't increase its value to anyone, except perhaps Mr. Smith. Likewise, the price-raising capacity of any given name can vary over time. The name Ambercrombie \& Fitch once was highly valued, being associated with the likes of Teddy Roosevelt and Ernest Hemingway. It fell upon hard times by the 1970s before being successfully resurrected by The Limited (Carbone, 2004).

Hence, a particular brand's capacity to command higher prices is like a capital asset whose magnitude varies over time and that deserves to be managed carefully. This paper models a key issue in brand management, namely the preservation of "brand image" in the face of short-term opportunities that risk "brand dilution." The basic ideas are familiar from brand management texts, but were deliciously described in a special Fashion Survey issue of The Economist (March 6-12, 2004, p.7), which used the term "brand integrity" rather than "brand image".

"Like everyone else in the luxury goods market, all three (Richemont, Gucci, Pinault-Printemps-Redoute) face the challenge of maintaining "brand integrity" - analyst-speak for that indefinable aura that convinces a consumer to pay a lot of money for something he, or more likely she, could buy much 
more cheaply elsewhere. ... The destroyer of brand integrity is "brand dilution", which is the perverse reward for popularity. If too many people have a supposedly exclusive Fendi handbag or Hermès scarf, it is no longer exclusive, and therefore, in the customer's view, no longer worth its vertiginous price."

So the central decision for a fashion house is sales volume. Selling too few forfeits profit opportunities; selling too many dilutes brand image. To prevent brand dilution, firms that produce prestige goods use exclusive channels to restrict the availability of their products (Amaldoss and Jain, 2005a). Christian Dior sued supermarkets for carrying its products because wide availability could hurt the firm (Marketing Week, 1997). Likewise, luxury goods manufacturers are advised not to sell products over the Internet because doing so might dilute their image (Curtis, 2000).

Note that since the "product" in this case is really the brand, not a specific single product, selling very few also risks brand obscurity not exclusivity. That is, Hedi Slimane might make only one copy of a particular dress (e.g., for actresses like Sara Jessica Parker or Nicole Kidman to wear to the Oscars), but Slimane has to sell enough dresses in total over the year to be a trend-setting player. From the customers' perspective, a brand name has no value if the people one is trying to impress by flaunting the brand have never heard of it.

Changes in brand image are not instantaneous; they occur over time. Otherwise there would be no temptation to over-supply. Instead, a brand's value adjusts progressively to match its actual exclusivity or commonness.

As remarked by Amaldoss and Jain (2005a,b), this topic is related to the network goods literature (see, e.g., Katz and Shapiro, 1994). In most network goods models the network externalities are positive. However, brand dilution implies that the value of the brand decreases with the number of users, so we have a consumption externality that can be negative. Another difference with network externalities is that here the consumption externality is caused by social behavior rather than being technologically motivated.

As always, sales volume is intimately inter-related with price, but unlike typical goods, for high fashion it makes sense to view the key decision variable as sales volume. For a commodity, sales are expanded by cutting prices, but for high fashion, price is to some extent determined by the brand's position in the status hierarchy ${ }^{1}$. Cutting prices

\footnotetext{
${ }^{1}$ The Economist also notes (p.14) "At the top end of the market the commercial arithmetic allows a certain amount of leeway [on price] because the shopper is willing to pay up to $\$ 2000$ for her dress, everyone is happy. Go downmarket from Barneys, however, to the Gap and Macy's in America, or to
} 
can even reduce the fashion good's signaling value. There are other, potentially more appealing alternatives for expanding sales, such as expanding the number of retail stores allowed to carry the brand. Indeed, a significant part of The Economist article dwelled on the issue of licensing as a mechanism for expanding sales and its risks of brand dilution. With licensing, sales expansion involves allowing the brand to be attached to more and more different types of products (e.g., not just Pierre Cardin suits, but also Pierre Cardin shirts and even toilet seat covers).

The problem with excessive licensing could lie in the long term, as is explained in the Economist Survey (p.8).

"If a licensee sells the product at a discount, or lowers its quality, or sells it in the wrong place, or bundles it together with low-quality products, the "brand integrity" will be harmed, perhaps permanently. The best-known example is Pierre Cardin, whose licensing operations proliferated so much that by the 1980s he had lent his name up to 800 products, including toilet-seat covers. In the end, despite his talents as a couturier, he became too common for many high-fashion customers. Mr. Cardin, rolling in his royalties, did not seem to care."

One of the aims of this paper is to examine under what kind of scenarios the "Pierre Cardin policy" can be optimal, from a profit maximizing point of view.

The fashion industry is just one industry that faces "conspicuous consumption". The consumer decision to buy a "conspicuous" product depends not only on the product's functionality, but also on social needs such as prestige (Amaldoss and Jain, 2005a,b; Belk, 1988; Grubb and Grathwohl, 1967; Leibenstein, 1950, Chao and Schor, 1998). Besides fashion, other conspicuous products include expensive cars, coins, watches and jewelry. The analysis in this paper applies more broadly to conspicuous consumption goods generally, not just to fashion goods alone. However, for matters of interpretation we continue to use the term "fashion" throughout the paper.

There are various models of conspicuous consumption in the literature, but most try to document or explain the behavior, not tell firms how to exploit it, as we do. Amaldoss and Jain $(2005 \mathrm{a}, 2005 \mathrm{~b})$ are recent exceptions that also adopt the firm optimization perspective. Amaldoss and Jain (2005b) employ rational expectations and consumer learning in a monopoly model to determine the optimal dynamic pricing policy in a Top Shop in Britian, or Printemps in France, and what counts most for the shopper is often price." 
conspicuous goods market. They find that, if the market is comprised of both snobs and followers, then more snobs might buy as price increases. Amaldoss and Jain (2005a) generalize this result to a duopoly situation.

The present paper differs from Amaldoss and Jain (2005a, 2005b) by having the firm pick its point along the demand curve by specifying sales volume rather than price, but more fundamentally by treating the control as being continuous in time. In a sense, we capture what Amaldoss and Jain (2005a, pp.40-41) expect from further research if their one-period model is extended to a dynamic one:

"For example, increased sales in earlier periods are likely to decrease the demand in the later periods if there is any snobbishness in the market."

In particular, we show that three different policies are viable for the fashion designer. The first policy carefully builds up brand image over time, which eventually converges to a constant level. The second pertains to the case when the current brand image value is low and it would take so long to build up brand image that it is better to stop (or refrain from start) being active in the fashion industry. The third policy (Pierre Cardin) is an option when there is a high current brand image level. Then if brand image adjusts slowly, the discount rate is high and/or production costs are large, it may be best to go for short term profits by producing at the maximal level and then leaving the business in some finite time. We also identify the conditions under which each of these three candidate strategies is optimal.

The paper is organized as follows. Section 2 presents and analyzes the model, while the results are reported in Section 3. Section 4 concludes.

\section{The Model}

The considerations above suggest investigating a model of the following form. The state variable $A(t)$ denotes the firm's brand image, while the control variable $Q(t)$ is the sales level. $h(Q)$ stands for the long term brand image level that is reached when sales are constant over time and equal to $Q$. The function $h(Q)$ is hump-shaped for the reasons discussed in the Introduction. Generally the greater the sales volume, the greater the dilution and the lower the brand value, except that if volume is too low, no one will even have heard of the brand. Loosely, if the public sees just one person wearing a fashion, it's liable to look odd. When a second person joins the first, the fashion can become 
chic. When scores more imitate, it becomes a mere fad, to be shunned by the fashion elite. Summarizing, we have:

$$
\begin{aligned}
h(0) & =0 \\
h(Q) & >0 \text { for } 0<Q<Q_{1}, \\
h(Q) & <0 \text { for } Q_{1} \leq Q \text { (brand dilution), } \\
h^{\prime}(Q) & >0 \text { for } 0 \leq Q<Q^{*} \text { (increasing visibility in the market) } \\
h^{\prime}(Q) & =0 \text { for } Q=Q^{*} \\
h^{\prime}(Q) & <0 \text { for } Q^{*}<Q \text { (brand dilution), }
\end{aligned}
$$

where $Q^{*}$ is the sales volume that leads to the maximum value

$$
A_{M}=h\left(Q^{*}\right)
$$

the brand image $h(Q)$ the firm can reach in the long term.

The development of brand image over time is assumed to depend linearly on the difference between "long term brand image" $h(Q)$ and current brand image $A$ :

$$
\dot{A}=k[h(Q)-A], \quad A(0)=A_{0} \geq 0,
$$

where $k$ is the adjustment parameter. One question is what exactly is meant by the reputation at time zero $(A(0))$ and why it isn't always the case that $A(0)=0$. There are three reasons why $A(0)$ might be positive. First, a new entrant might launch a largescale advertising campaign designed to establish a brand identity. The optimization problem considered here then pertains to what the firm should do after that campaign has established an initial reputation, and one might view there to be an implicit side constraint that the present value of the profit stream must be at least large enough to offset the expense of the initial advertising campaign.

Second, sometimes a person who has developed name recognition in one domain launches activities in another, and connotations with the name from the first domain carry over. For example, George Foreman established his reputation as a boxer, and it helped him market an extremely successful line of grilling equipment. Likewise Arnold Schwarzenegger became famous through movies and his wife Maria Shriver came from America's most prominent political family, so when they opened their restaurant "Schatzi's on Main" in Santa Monica it instantly had cachet. ${ }^{2}$

\footnotetext{
${ }^{2}$ The George Foreman Grill, introduced in 1995, has been described by Forbes.com as perhaps the best selling small appliance in history (http://www.forbes.com/businesswire/feeds/businesswire/

2004/08/18/businesswire20040818005134r1.html). Schatzi's on Main is profiled by Seeing the Stars (http://www.seeing-stars.com/Dine/Schatzi.shtml) as a celebrity haunt.
} 
Third, the world is already full of brands with established identities. The model could apply to managing an existing brand from this point forward.

The firm's objective is to maximize its discounted cash flow stream. Defining $p(A)$ as the unit price of sales which is increasing in brand image $\left(p^{\prime}>0, p(0)=0\right), c$ being the constant unit cost, and $\bar{Q}$ the firm's capacity limit ${ }^{3}$, we arrive at the following model:

$$
\operatorname{Max}_{Q} \int_{0}^{\infty} e^{-r t}(p(A) Q-c Q) d t
$$

subject to

$$
\dot{A}=k[h(Q)-A], \quad A(0)=A_{0} \geq 0,
$$

and

$$
0 \leq Q \leq \bar{Q}
$$

Here the firm chooses production volume, while price is completely determined by $A$. The non-negativity of $A$ is ensured, because it is never optimal for the fashion designer to have $A<0$, since this would give a negative unit price of sales. Negativity of $A$ is easy to prevent by putting $Q=0$ as soon as $A$ is close to zero.

Unlike the usual microeconomic framework, here price depends indirectly but not directly on quantity. This would indeed be problematic if the time horizon were short. However, in our long term model there is room for delayed price responses. The proximate determinant of price is brand image, which in turn is influenced by quantity via the term $h(Q)$. The idea here is that sales volume can be chosen freely, while brand image, and thus also price, adjusts with a lag. We believe that this is how it works with fashion brands: Mr. Cardin's policy is such that at the moment that $A$ is large $Q$ is raised to exploit the high unit price $p(A)$ to make high short-term profits. However, in the long term brand image and hence price falls via the term $h(Q)$. Apparently such a policy is more profitable when the adjustment parameter $k$ is low. Another argument for price being a function of brand image alone and not of quantity, is that quantity $Q$ need not be related to one market. Instead, products can be different as is reflected by the Economist citation in the Introduction, in which it is mentioned that Pierre Cardin "had lent his name up to 800 products".

To derive the optimal solution, we first specify some functional forms satisfying the properties described above:

$$
\begin{aligned}
p(A) & =2 \sqrt{A} \\
h(Q) & =\alpha Q-\beta Q^{2} .
\end{aligned}
$$

\footnotetext{
${ }^{3}$ In the analysis to follow we assume that $\bar{Q}>Q^{*}$.
} 
The Hamiltonian $H$ for this problem is given by

$$
H=2 Q \sqrt{A}-c Q+\lambda k\left[\alpha Q-\beta Q^{2}-A\right]
$$

Consequently, the adjoint equation is

$$
\dot{\lambda}=r \lambda-H_{A}=[r+k] \lambda-\frac{Q}{\sqrt{A}}
$$

while the optimal sales volume must satisfy

$$
H_{Q}=2 \sqrt{A}-c+\lambda k[\alpha-2 \beta Q]\left\{\begin{array}{c}
< \\
= \\
>
\end{array}\right\} 0 \text { if }\left\{\begin{array}{c}
Q=0 \\
0<Q<\bar{Q} \\
Q=\bar{Q}
\end{array}\right\} .
$$

Provided that $\lambda$ is nonzero (in fact, it will turn out that $\lambda>0$ for $Q>0$ ), for optimal trajectories it holds that

$$
Q=Q^{*} \Longleftrightarrow 2 \sqrt{A}=c
$$

Hence, every optimal trajectory passes through one unique point when $Q=Q^{*}$. This is similar to the critical point obtained in Caulkins et al. (2003, p.9).

Differentiating (5) with respect to time eventually gives:

$$
\dot{Q}=\frac{\alpha-2 \beta Q}{-2 \beta A^{1 / 2}\left[2 A^{1 / 2}-c\right]}\left[k \beta Q^{2}+r\left[c A^{1 / 2}-2 A\right]+k\left[c A^{1 / 2}-3 A\right]\right] .
$$

Hence, $\dot{Q}=0$ either occurs for

$$
\alpha-2 \beta Q=0
$$

or

$$
k \beta Q^{2}+r\left[c A^{1 / 2}-2 A\right]+k\left[c A^{1 / 2}-3 A\right]=0,
$$

while $\dot{Q}$ changes sign when $2 A^{1 / 2}-c=0$, i.e., at

$$
A_{Z}=\frac{c^{2}}{4}
$$

Notice that (8) only satisfies the necessary condition (5) when $2 \sqrt{A}=c$ (cf. (6)). The following proposition exhibits some stability properties. 
Proposition 1 Assume that a steady state $(\hat{Q}, \hat{A})$ exists and that $\hat{Q}>Q^{*}$. Then this steady state is

i) a saddle point if

$$
2 \sqrt{\hat{A}}>c, \quad \text { i.e. }, \quad \hat{A}>A_{Z}
$$

ii) unstable if

$$
2 \sqrt{\hat{A}}<c, \quad \text { i.e., } \quad \hat{A}<A_{Z} .
$$

Proof. From (1) it is directly obtained that

$$
\begin{aligned}
& \frac{\partial \dot{A}}{\partial A}=-k<0 . \\
& \frac{\partial \dot{A}}{\partial Q}=k h^{\prime}\left(\begin{array}{l}
> \\
<
\end{array}\right) 0 \text { for } Q\left(\begin{array}{l}
< \\
>
\end{array}\right) Q^{*} .
\end{aligned}
$$

Equation (7), being evaluated at $\dot{A}=0$ and given that (9) holds, leads to

$$
\begin{aligned}
& \frac{\partial \dot{Q}}{\partial Q}=-\frac{k A^{-1 / 2} Q[\alpha-2 \beta Q]}{2 \sqrt{A}-c}\left(\begin{array}{l}
< \\
> \\
< \\
>
\end{array}\right) \text { for }\left(\begin{array}{l}
Q>Q^{*} \text { and } 2 \sqrt{A}<c \\
Q>Q^{*} \text { and } 2 \sqrt{A}>c \\
Q<Q^{*} \text { and } 2 \sqrt{A}>c \\
Q<Q^{*} \text { and } 2 \sqrt{A}<c
\end{array}\right), \\
& \left.\frac{\partial \dot{Q}}{\partial A}=\frac{A^{-3 / 2}[\alpha-2 \beta Q]}{2 \beta[2 \sqrt{A}-c]}[r+2 k] A-\frac{k}{2}[\alpha-2 \beta Q] Q\right]\left(\begin{array}{l}
< \\
>
\end{array}\right) 0 \text { for }\left(\begin{array}{l}
Q>Q^{*} \text { and } 2 \sqrt{A}>c \\
Q>Q^{*} \text { and } 2 \sqrt{A}<c
\end{array}\right) .
\end{aligned}
$$

A steady state is a saddle point if the determinant of the Jacobian is negative, i.e.

$$
\frac{\partial \dot{Q}}{\partial Q} \frac{\partial \dot{A}}{\partial A}-\frac{\partial \dot{Q}}{\partial A} \frac{\partial \dot{A}}{\partial Q}<0 .
$$

In case $Q>Q^{*}$ and $2 \sqrt{A}>c$, it holds that $\frac{\partial \dot{A}}{\partial Q}, \frac{\partial \dot{A}}{\partial A}$, and $\frac{\partial \dot{Q}}{\partial A}$ are negative, while $\frac{\partial \dot{Q}}{\partial Q}$ is positive, which implies that the determinant of the Jacobian is negative, thus we have a saddle point. For the case $Q>Q^{*}$ and $2 \sqrt{A}<c$, it holds that $\frac{\partial \dot{A}}{\partial Q}, \frac{\partial \dot{A}}{\partial A}$, and $\frac{\partial \dot{Q}}{\partial Q}$ are negative, while $\frac{\partial \dot{Q}}{\partial A}$ is positive, which implies that the determinant of the Jacobian is positive, and thus instability.

Note that this proposition does not have a stability result for $Q<Q^{*}$. However, this is not that crucial, since a sales volume can only be viable in the long run if $Q>Q^{*}$. Note that, since $Q<Q^{*}$ implies that $p(A)=2 \sqrt{A}<c$, from an economic point of view it is hard to imagine that a firm ends up in a steady state where it will always makes a loss when it could instead go out of business and make neither a profit nor a loss.

The next proposition identifies the two relevant scenarios. 
Proposition 2 Low unit cost scenario: If

$$
c<\frac{\alpha}{\sqrt{\beta}}
$$

then two interior steady states exist, the larger one being a saddle point located in the relevant region $A>A_{Z}$.

High unit cost scenario: If

$$
c>\frac{\alpha}{\sqrt{\beta}}
$$

then there is no interior steady state in the relevant region $A>A_{Z}$.

Proof. Define $\left(A_{Y}, Q^{*}\right)$ with

$$
A_{Y}=\left(\frac{c(r+k)+\sqrt{c^{2}(r+k)^{2}+(2 r+3 k) \frac{k \alpha^{2}}{\beta}}}{2(2 r+3 k)}\right)^{2}
$$

as the intersection point of the isocline $\dot{Q}=0$ with the horizontal $Q=Q^{*}$ line. Rather long but straightforward calculations show that

$$
\begin{aligned}
& c<\frac{\alpha}{\sqrt{\beta}} \Longleftrightarrow A_{Z}<A_{Y}<A_{M} \quad \text { and } \\
& c>\frac{\alpha}{\sqrt{\beta}} \Longleftrightarrow A_{M}<A_{Y}<A_{Z} .
\end{aligned}
$$

In the low unit cost scenario, it is now easily derived that there are two interior steady states. The larger one is located in the positive profit region $A>A_{Z}$ and because of Proposition 1 it is a saddle point. The smaller interior steady state is unstable.

An analogous proof shows that in the high unit cost scenario, no steady state in the positive profit region $A>A_{Z}$ exists $^{4}$.

Besides an interior saddle point equilibrium, an optimal trajectory could also end as a boundary $\operatorname{arc} Q=0$. There we have

$$
\begin{aligned}
\dot{A} & =-k A, \\
\dot{\lambda} & =[r+k] \lambda .
\end{aligned}
$$

In order for $\lambda$ to remain finite, this implies that $\lambda=0$. The maximum principle is satisfied since $Q=0$ gives

$$
H_{Q}=2 \sqrt{A}-c+\lambda k \alpha=2 \sqrt{A}-c \leq 0,
$$

\footnotetext{
${ }^{4}$ Note that two interior steady states might occur in the region $A<A_{Z}$ which however cannot be long run optimal equilibria since the profit would be negative there (cf. Proposition 1).
} 
which holds when the "profit margin is negative". Hence, a policy with $Q=0$ can only occur in case $p(A)=2 \sqrt{A}<c$.

Proposition 2 learns that the distinction between low and high unit costs is important, where the boundary between the scenarios is the unit cost level $\alpha / \sqrt{\beta}$. The other parameters $k, r$ and $\bar{Q}$ thus do not affect the qualitative results. At most they influence the location of the saddle point, which holds for $k$ and $r$. To illustrate the low unit cost scenario of Proposition 2, we now employ a numerical example. In the next section we use this example with variations of $c$ to draw phase diagrams for both the low and high unit cost scenario. The parameter values are:

$$
\beta=1, \alpha=2, c=1, k=0.1, r=0.1, \bar{Q}=2.25 \text {. }
$$

The $\dot{A}=0$-isocline is given by

$$
A=2 Q-Q^{2}
$$

while, as a result of $(9)$, the $\dot{Q}=0$-isocline is

$$
Q^{2}=-2 A^{1 / 2}+5 A
$$

Notice that the $\dot{Q}=0$-isocline goes through $(0,0)$, is non-existent for $A \in(0, \bar{A})$, where

$$
\bar{A}=\frac{4}{25}
$$

and is existing for $A \in\left[\frac{4}{25}, \infty\right)$. On this latter interval it holds that

$$
Q=\left[-2 A^{1 / 2}+5 A\right]^{1 / 2} \text {. }
$$

From (12) and (13) it is obtained that we have three steady states:

$$
\begin{aligned}
& \left(\hat{A}_{0}, \hat{Q}_{0}\right)=(0,0) \\
& \left(\hat{A}_{1}, \hat{Q}_{1}\right)=(0.1628848,0.0851116), \quad\left(\hat{A}_{2}, \hat{Q}_{2}\right)=(0.7834905,1.4653165) .
\end{aligned}
$$

According to Proposition $1,\left(\hat{A}_{2}, \hat{Q}_{2}\right)$ is a saddle point. Simple calculations reveal that $\left(\hat{A}_{1}, \hat{Q}_{1}\right)$ is unstable.

\section{Results}

Still using the parameter values $\alpha=2, \beta=1, k=0.1, r=0.1, \bar{Q}=2.25$, we vary $c$ in order to identify two different cases. First we present the case of an interior equilibrium 
that occurs for $c$ small. Here the firm survives in the long run by keeping a constant brand image level. The other case is a boundary equilibrium which occurs for large unit cost $c$. Here the firm exploits its reputation to maximize short run profits. Brand dilution eventually results in negative profits causing the firm to leave business.

c small: interior equilibrium We start with small unit $\operatorname{costs} c<\frac{\alpha}{\sqrt{\beta}}=2$, e.g., $c=1$. The result is depicted in Figure 1, where we have a saddle point equilibrium and a boundary equilibrium $\hat{A}_{0}=\hat{Q}_{0}=0$. From an economic point of view convergence to the saddle point $\left(\hat{A}_{2}, \hat{Q}_{2}\right)$ is understandable since it holds there that $p(A)>c$ and $Q>Q^{*}$. Note that $p(A)>c$ implies that the firm makes positive profits in the steady state. It would not make sense to converge to a steady state where the opposite holds, i.e., $p(A)<c$, so that the firm would make a loss forever.

In an optimal steady state we also have that $Q>Q^{*}$. In steady state it holds that $A=h(Q)$, and for each given $A$, there are two $Q$ values satisfying this equality, one with $Q<Q^{*}$ and one with $Q>Q^{*}$. Since $p(A)>c$, the firm would like to choose a $Q$ as large as possible, so given the choice between a $Q<Q^{*}$ and a $Q>Q^{*}$, it will always choose the latter one.

A sensible alternative for converging to a steady state with $p(A)>c$ and $Q>Q^{*}$ would occur if for some initial state some heavy losses have to be incurred first before a profitable steady state is reached. Increasing $Q$ implies increased costs due to the term $c Q$, and if $k$ is low, $A$ adjusts slowly, implying that also the output price will go up slowly. In such a case it can be preferable to leave business immediately, thus choosing a trajectory where $Q=0$, ending up with $\left(\hat{A}_{0}, \hat{Q}_{0}\right)=(0,0)$. As we know from the previous section, this boundary equilibrium can only occur when the profit margin is negative, implying that it must be located to the left of $A_{Z}=0.25$. This all suggests the existence of a Skiba point (Skiba, 1978; Dechert and Nishimura, 1983), $A_{S}$, implying that for lower values of brand image initial losses on the saddle point path are so large that it is better to go out of business. To the right of the Skiba point the saddle point path is optimal.

We conclude that when $A(0)=0$, the optimal solution is not to enter the fashion market. However, since the Skiba threshold is to the left of the $p(A)=c$ line, entering the market is not conditional on the initial reputation being so favorable that profits are reaped from the first moment. So it may be profitable for someone with some degree of brand recognition to incur losses while investing in improving brand image, even if the average readers of this journal might be well advised to keep their day jobs rather than 


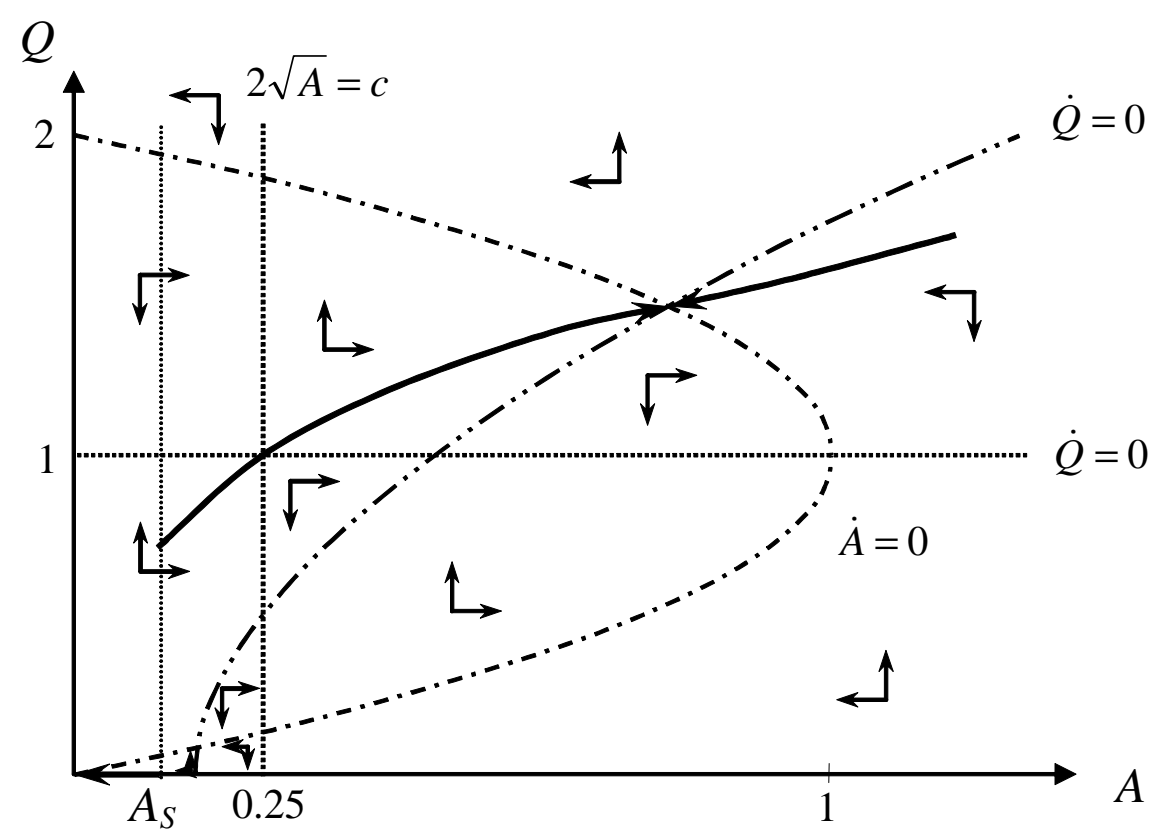

Figure 1: Optimal policy in case of parameter values $\alpha=2, \beta=1, k=0.1, r=0.1$, $\bar{Q}=2.25$ and small unit costs, $c=1$.

launching their own designer labels.

At first sight, when initially the profit margin is positive, an alternative candidate for optimality may be starting out with $Q=\bar{Q}$ for $p(A)>c$. Then, due to brand dilution brand image starts to decrease. The firm leaves business as soon as brand image is so small that the profit margin becomes negative, i.e. $Q=0$ for $p(A) \leq c$. The advantage of this policy is that the firm initially exploits the high profit margin by pushing up sales to its maximum, which is especially attractive when the discount rate is high. The drawback is that due to brand dilution, the profit margin eventually becomes negative so that the firm is forced to leave business in finite time. This policy actually appears to be optimal for a higher value of the unit cost (see Figure 2 later on), but here is dominated by admitting the saddle path policy at the moment that $p(A)$ hits $c$. The reason is that this saddle path policy generates positive profits, while a policy with $Q=0$ automatically leads to zero profits. Notice that initially starting with $Q=\bar{Q}$ followed by the saddle path policy from $p(A)=c$ onwards, implies that $A$ is decreasing first, while it is increasing later on. For this reason it cannot be an optimal trajectory, because at least since Hartl (1987) it has been known that for a one-state optimal control model the optimal policy must be monotonic in the state. 
c large: boundary equilibrium According to Proposition 2, the large unit cost scenario corresponds to $c>\frac{\alpha}{\sqrt{\beta}}=2$. Figure 2 depicts the solution when the unit cost $c$ equals 2.2. Here we have a boundary equilibrium, which shares some characteristics of the policy applied by Pierre Cardin. As long as the profit margin is positive, the firm sets $Q=\bar{Q}$, while it leaves business at the moment brand dilution has resulted in a negative profit margin. Hence, instead of converging to a positive steady state, for a high initial value of brand image a higher sales level will be chosen to exploit the high output price. The result is that brand dilution kicks in, resulting in a decrease of $A$, and the trajectory eventually ends up in $(0,0)$.

One question raised by Figure 2 is, if for these parameters it is optimal to drive a brand name into the ground, why would one ever start with an initial brand image greater than that such that $p(A)=c$ ? In addition to the possibility mentioned above of importing a brand image by virtue of accomplishments in another domain, there is also the possibility that market conditions can change unexpectedly. For various reasons, parameters may have been such that the optimal strategy was to build up brand image (e.g., before $c=1$ ) but now the parameters have changed, making it undesirable to remain in the market in the long run but raising the question as to what is the best exit strategy.

\section{Conclusions}

A fashion good's brand image denotes to what extend a consumer is willing to pay extra money to obtain the particular brand, while at the same time another product of similar quality could be purchased at a cheaper price. As a result profit margins of fashion goods mainly depend on brand image. For this reason it is important to manage the value of brand image carefully over time. This paper provides a quantitative framework to support this managerial decision problem.

Brand image is like an asset that can be built up over time. The way to do this is not trivial, however. On the one hand it is important to keep the fashion good exclusive: in the view of the "upper ten", a good is no longer worth its vertiginous price if too many others have already bought it. Hence, here consumers value the product less when more of them own it (Amaldoss and Jain, 2005a). This implies that sales should be limited to a certain extent in order to prevent the brand from becoming too common. An example related to another conspicuous product is that Ferrari promises that it will not produce more than 4300 vehicles despite more than a two-year waiting list for its cars (Amaldoss 


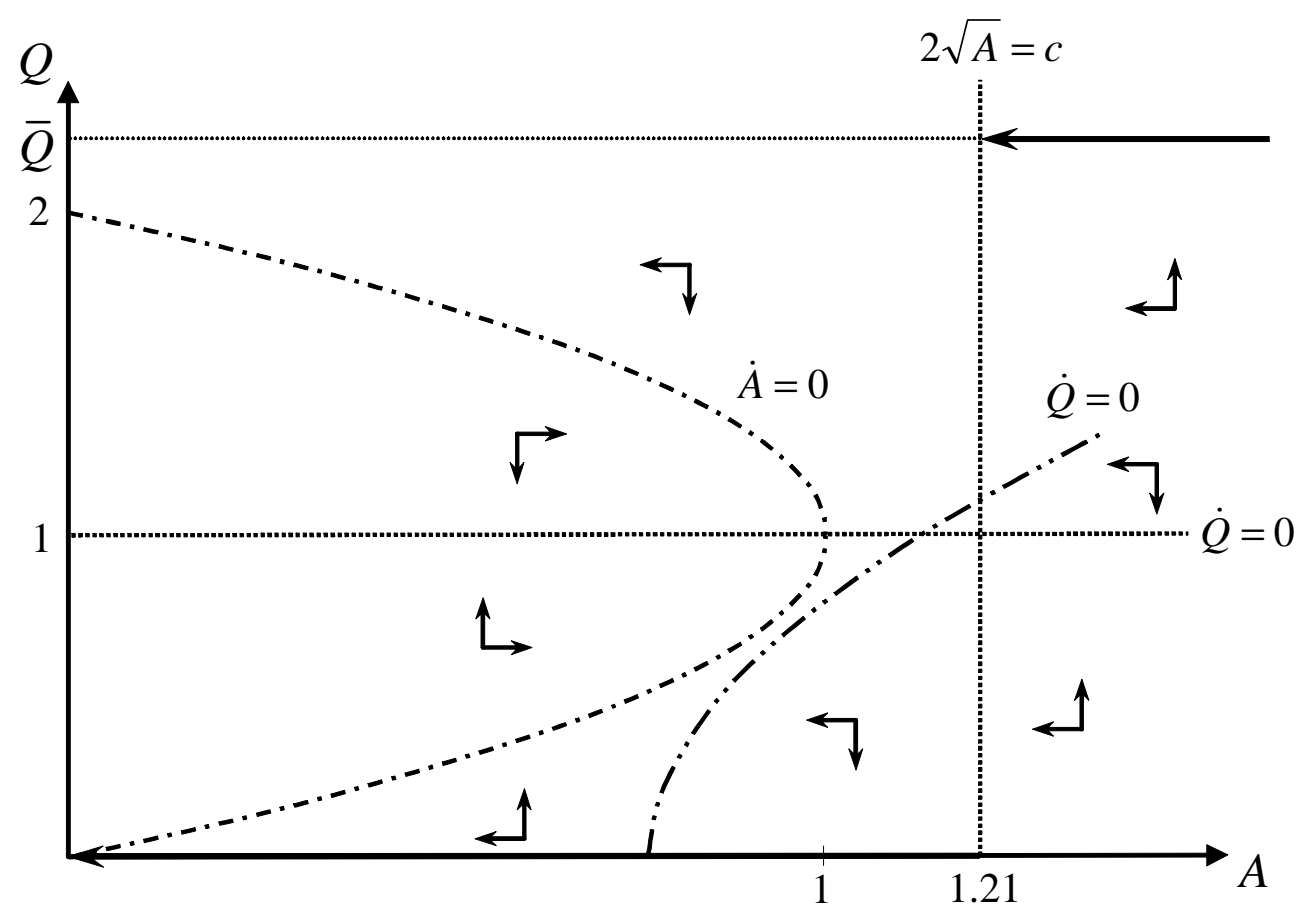

Figure 2: Optimal policy in case of parameter values $\alpha=2, \beta=1, k=0.1, r=0.1$, $\bar{Q}=2.25$ and large unit costs, $c=2.2$.

and Jain, 2005b; Betts, 2002). On the other hand, in order to build up a famous brand the good must also be visible enough, which requires a sufficient amount of sales. According to another Economist article (October 2-8, 2004, pp.61-62), the fashion designer Giorgio Armani did a good job in carefully managing his brand image. It was noted that Mr. Armani has been steadily profitable for thirty years, while he diversifies into new lines without cheapening his brand. Francoise Paumard, a luxury-goods analyst at Exane BNP Paribas in Paris, says that

"Armani managed to democratize the brand and keep it exclusive".

In his clash with Luxortica management, which is one of the few he allowed to use his brand, he insisted that

"they should be made more exclusive by restricting sales".

In the same article it becomes clear that managing the brand image is not a trivial job:

"He also managed to avoid some of his rivals' mistakes. Led by France's Pierre Cardin, the pioneer of fashion licenses, Christina Dior, Yves Saint 
Laurent and many Italian designers allowed others to use their brands. But

Mr. Armani kept a handful of licenses under tight control."

Our dynamic analysis shows that for different scenarios different candidates for an optimal policy are possible. A first candidate carefully builds up brand image over time, where brand image eventually converges to a long run equilibrium value. Such a policy can even be optimal if initially brand image is so low that starting production of the good implies that in the short term only losses will be made.

The second candidate prescribes stopping (or to refrain from starting up) being a producer of fashion goods. This occurs when the initial brand image value is so low that initial losses are too severe to sustain while waiting until the good becomes profitable. This will occur in scenarios where it takes too long to build up sufficient brand image, or when the fashion designer's discount rate is too high.

The third candidate occurs when initially brand image is such that the fashion good has a high profit margin. Instead of keeping it that way, as in the first policy candidate, it could instead be optimal to milk the high price of the fashion good by selling at the maximal amount. The implications are that in the short term profit is maximized, but in the longer term the good becomes too common for high fashion customers. This implies that the price of the fashion good will drop over time. In the fashion industry this phenomenon is known as brand dilution. This policy of aiming at short term profits, which in practice is applied by the couturier Pierre Cardin, turns out to be optimal in the case of high unit costs, a large discount rate, and/or a brand image value that adjusts slowly over time.

Acknowledgement The authors would like to thank two anonymous referees for their comments.

\section{References}

[1] Amaldoss, W., Jain, S., Pricing of conspicuous goods: a competitive analysis of social effects, Journal of Marketing Research, 42, 30-42, 2005a.

[2] Amaldoss, W., Jain, S., Conspicuous consumption and sophisticated thinking, to appear in Management Science, 2005b.

[3] Bagwell, Laurie Simon, Bernheim, B. Douglas., Veblen effects in a theory of conspicuous consumption, The American Economic Review, 86(3), 349-373, 1996. 
[4] Belk, Russel W., Possession and extended self, Journal of Consumer Research, 15(2), 139-168, 1988.

[5] Berkowitz, Eric N., Kerin, Roger A., Hartley, Steven W., Marketing, 6th ed., McGraw-Hill/Irwin, New York, 2000.

[6] Betts, P., National hero bearing the burden of success, Financial Times, April 11, 2002 .

[7] Bianchi, M., Novelty, preferences, and fashion: when goods are unsettling. Journal of Economic Behavior \& Organization, 47(1), 1-18, 2002.

[8] Bikhchandani, S., Hirshleifer, D., Welch,I., A theory of fads, fashion, custom, and cultural-change as information cascades, Journal of Political Economy, 100(5), 9921026, 1992.

[9] Boone, Louis E., Kurtz, David L., Contemporary Marketing, Dryden Press, Orlando, 1999.

[10] Carbone, Lewis P., Clued In: How to Keep Customers Coming Back Again and Again, Prentice-Hall, New York, 2004.

[11] Caulkins, J.P., Feichtinger, G., Johnson, M., Tragler, G., Yegorov, Y., Skiba thresholds in a model of controlled migration, Working Paper, 2003.

[12] Chao, Angela, Schor, Juliet B., Empirical tests of status consumption: Evidence from women's cosmetics, Journal of Economic Psychology, 19, 107-131, 1998.

[13] Coelho, Philip R.P., McClure, James E., Toward an economic theory of fashion, Economic Inquiry, 31(4), 595-608, 1993.

[14] Corneo, G., Jeanne, O., Segmented communication and fashionable behavior, Journal of Economic Behavior \& Organization. 39(4), 371-385, 1999.

[15] Curtis, J., Not taking luxury for granted: the luxury goods sector is thriving, but top brands need to find a balance between widening appeal and maintaining their exclusivity, Marketing, August 24, 2000.

[16] Dechert, D.W., Nishimura, K., Complete characterization of optimal growth paths in an aggregated model with a nonconcave production function, Journal of Economic Theory, 31, 332-354, 1983. 
[17] Rags and riches: A survey of fashion, The Economist, March 6th, 2004.

[18] King of the catwalk, The Economist, October 2nd, 61-62, 2004.

[19] Frijters, P., A model of fashion and status, Economic Modeling, 15(4), 501-517, 1998.

[20] Grubb, Edward, Grathwohl, Harrison, L, Consumer self-concept, symbolism, and market behavior: A theoretical approach, Journal of Marketing, 31(4), 22-27, 1967.

[21] Hartl, R.F., A simple proof of the monotonicity of the state trajectories in autonomous control problems, Journal of Economic Theory, 41, 211-215., 1987.

[22] Katz, M., Shapiro, C., Systems competition and network effects, Journal of Economic Perspectives, 8(2), 93-115, 1994.

[23] Leibenstein, H., Bandwagon, snob, and Veblen effects in the theory of consumers' demand, Quarterly Journal of Economics, 64(2), 183-207, 1950.

[24] Discovery thwart luxury scent market, Marketing Week, 14, 43, 1997.

[25] Perreault, William, McCarthy, Jerome, Essentials of Marketing: A Global Approach, 8th ed., McGraw-Hill/Irwin, New York, 2000.

[26] Skiba, A.K., Optimal growth with a convex-concave production function, Econometrica, 46, 527-539, 1978. 